\title{
AN APPLICATION OF A COMMUNITY PSYCHOLOGY APPROACH TO DEALING WITH FARM STRESS
}

\author{
NIKKI GERRARD \\ Saskatchewan Health, Saskatoon
}

\begin{abstract}
Community psychology arose in the 1960 s, in the United States, as a response to: (a) pressure to move toward more community based mental health services, and (b) clinical psychologists asking themselves why they were individually treating and conceptualizing large numbers of people who had similar presenting problems. They realized that the social context of their clients' lives was paramount in determining their emotional health. In 1990 , I brought a community psychology perspective to designing and implementing a farm stress program in Saskatchewan. I describe how community psychology values and practices, community development, and mental health promotion are applied to this program. I discuss the value of conceptualizing mental health issues, such as farm stress, from the perspective of individuals-in-communities and discuss considerations for future applications of a community psychology approach to similar and other mental health issues.
\end{abstract}

\section{INTRODUCTION}

Community psychologists are interested in the psyche of communities-in other words, in the collective spirit, energy, mind set, identity, activities, and perspectives of the individuals who make up a community. By applying the values and practices of community psychology, they focus on people's and communities' strengths and work to enhance those strengths. In addition, community psychologists often get involved in community development and mental health promotion.

In this paper, 1 review the background of community psychology as a discipline and demonstrate how, to address the problem of farm stress in Saskatchewan, its values and practices have been applied-through a non-traditional, community-based program-to farmers. I conclude by providing a discussion of considerations for future applications of a community psychology approach to similar and different rural and urban mental health issues.

\section{HISTORY AND PRACTICE OF COMMUNITY PSYCHOLOGY}

Community psychology arose in the 1960 s in the United States as a response to the call for a more community-based approach to mental health services (for an extensive history of community psychology, sec Phares \& Trull, 1997). Community psychologists saw that an intra-psychic approach was inadequate to address problems which clearly were embedded in a social context. Rappaport (1977), in 
fact. stated that the paradigms of clinical psychology actually had a disrespect for individual and cultural differences. Some clinical psychologists started to see a link between large numbers of people who had similar presenting problems. Early community psychologists focused on women. African-Americans, and working class people. At the Ontario Institute for Studies in Education (OISE), University of Toronto, where I received my training, a graduate program in community psychology began within the Applied Psychology department in the early 1980s. While most of the research areas within this program dealt with urban issues, some dealt with Canadian and international co-operative and development work, much of which was rural. All community psychology programs-whether American or Canadian, rural or urban-share a focus on and understanding of the role of the social context in clients ${ }^{*}$ lives. This social context includes poverty, lack of employment and education, violence, and a host of other factors which are paramount in determining clients' (and communities') emotional health.

The practice of a community psychologist often includes conducting a needs assessment of the issue being addressed. Usually, the community which is to be affected by the community psychologist is at the centre of such a needs assessment and participates in it. This participation begins the process of empowering people, which is a core value of community psychology. Many programs involve some sort of social-action component, and education (as opposed to psychotherapy) is more often the mode of service delivery. Interventions are targeted at the community level (e.g. . group or other community services) rather than at individuals, couples, or families. The outcome expectation of a community psychologist's involvement is a strengthening of the community's capacity to deal with emotional adversity, regardless of the source of that adversity.

\section{METHOD: APPLICATION OF A COMMUNITY PSYCHOLOGY PERSPECTIVE TO FARM STRESS}

In 1990 , fresh with my doctorate in community psychology, I was hired by the Mental Health Clinic in Saskatoon, Saskatchewan to design and implement a province-wide community psychology approach to the issue of farm stress. The position, which had been empty for $1 \frac{1 / 2}{2}$ years, had been created by a clinical psychologist as a response to the farm crisis of the mid-1980s. Enlightened managers in the clinic wanted a less-clinical and less-traditional approach as a response to this problem, and were looking for more of a community-development focus. This approach was consistent with two other newer programs at the clinic (the alternatives to violence and the sex offenders treatment programs). Their vision fit well with my community psychology background, which was informed by years of social activism as a feminist and by extensive studies and experience in feminist psychology.

When I was hired, the clinic was part of the provincial health department's mental health services branch and was one of many main and satellite clinics around the province. However, in 1995, health reform resulted in the creation of 32 health districts, and I became an employee of the Saskatoon Health District. I still maintained a provincial focus, but my activities were greatly curtailed by the administrative boundaries of the separate health districts. I worked alone for six 
years, then the program expanded to include two more employees, who provided more traditional mental health services (such as individual counselling and rehabilitation services), mainly to clients within the Saskatoon Health District. Presently I am on contract to Saskatchewan Health as the provincial farm stress consultant.

Saskatchewan is primarily an agricultural province, with wheat as its main commodity. As such, it is susceptible to cycles of farm crises driven by any combination of: (a) weather extremes such as drought, too much rain, and/or early snow; (b) low commodity prices; and (c) high interest rates. In more recent years, with greater diversification of farming operations, additional crises have arisen because of low livestock prices (in, for example, massive hog productions).

Other emotional issues which are connected to stress and which affect farmers include financial problems, substance abuse, increased violence in the home, and suicides. An aging population, with fewer young people able to afford to enter farming, causes additional problems. As well, intergenerational issues regarding land transfer have created a great deal of stress for both the younger and older members of family farms.

\section{RESULTS}

\section{Development of Program}

In order to develop a program which would deal with the problem of farm stress, I built upon existing research (Gordon, 1990; Keating, 1987; Pipke, Svenson. \& Dreidger, 1987; Walker \& Walker, 1988). Within this body of work, previous researchers had highlighted the issues, revealed the areas of stress, and discussed the level at which various interventions had worked according to certain variables (such as age and gender). Some, in fact, had provided excellent resources (i.e. workbooks). Their work had not, however, resulted in the implementation of an actual farm-stress program.

I began by conducting a needs assessment with farmers and with those people who were providing direct services to farmers (i.e.. agrologists, public health workers, educators, clergy, etc.) (for a more thorough description of the needs assessment process, see Gerrard, 1995), The needs identified were as follows: education (about such things as stress management, anger management, self-esteem. and communication), $58 \%$; support group formation and maintenance, $21 \%$ : clinical services, $7 \%$; general information, $7 \%$; and, advocacy, $7 \%$. In addition, several themes emerged from the needs assessment-that is, the identified needs. When viewed together, further identified some common characteristics of the assessment participants. Collectively, these people exhibited: (a) a strong sense of individualism, (b) a lack of trust, (c) a paternalistic way of life. (d) a religion of hope, and (e) an aversion to stigma.

Historically, farmers have been strong individualists. Perhaps individualism is the ingredient needed in order to break the land, homestead it, survive adversities, and persevere in a context of extreme climate, geography, and soil. However, when things do go wrong on a farm, an individualistic framework exacerbates the problem. Farmers are more likely to assume sole responsibility for the problem. 
rather than to consider the external, uncontrollable forces which may have caused or contributed to it.

The lack of trust experienced by farmers is, I believe, a healthy paranoia. The reality is that, whenever a farm goes bankrupt or is foreclosed upon, others (often members of the same community) benefit: land often sells for less than its full value, and equipment and furnishings are auctioned off at bargain prices. This potential to profit by others' misfortunes inevitably leads to an edge of distrust in farming communities. Distrust is further created by government policies which are produced and changed on a regular basis, leaving farmers' livelihoods constantly unstable.

The paternalistic way of life which is evident in farm communities has its roots in two realities. First, Canadian farmers have a long history of dependency on government subsidies, and yet they have had little voice in the decision-making processes which result in these subsidies. Consequently, most farmers have come to feel powerless to affect their own futures. Second, most farms are patrilineally structured (i.e., they are transferred from father to son). This structure leads to hierarchial decision-making with the father (rarely the mother) at the top and then the children (rarely the daughters or daughters-in-law) below him. In this system, female children are the least empowered of all. Both of these situations promote a deference to authority which is insidious and, ultimately, permeates all aspects of farm life.

Living in the future is more than a pastime in farm communities; it is a way of life. Many times, it is the only thing that keeps people going from year to year. from crop to crop. Farming today is as much a gamble as a game of Black Jack. With so many uncontrollable variables, a large part of farming is hoping for better weather, better commodity prices, better interest rates, better government policies, and better subsidies. A frequent refrain here is. "This is next-year country;" the communities clearly live with what I call a religion of hope.

A final characteristic within farm communities is a fear of stigma. It is considered a disgrace to be perceived to be doing poorly or needing help. Some farmers who are totally broke will still go to Texas in the winter or buy a new halfton truck. Behind this façade is a history of pride, individualism, and a drive to continue on, despite all.

One of the reasons a community psychology approach works so well for farm stress is that the work is done in the streets, where people live-out in the community, at events, coffee rows (restaurants where rural people gather for morning coffee), meetings, and health fairs-and not behind closed doors in an office. I work in any number of capacities in a community: thus, 1 am able to interact with farmers in a variety of ways, many of which have nothing to do with a traditional mental health service. The philosophy of a community psychologist is that mental health work can be done anywhere at any time. The relative invisibility of it reduces the stigma which so many fear.

Those who were involved in the needs assessment emphasized that the program should not be called a farm stress program, because that had too many negative connotations for them. Together, we came up with The Rural Quality of Life Program (RQLP) as an alternative name. One way to build people's capacity of 
personal power (not power to control or dominate others, but personal power to have choices, make decisions, and act on those decisions) is to provide an opportunity for them to name their reality; in this case, it included naming the program.

\section{Components of Program}

The program which 1 designed was to be delivered, in terms of time allotment, proportionally to the needs identified in the assessment-that is, I planned to spend $58 \%$ of my non-travel time providing education, $21 \%$ of my time developing and helping to maintain support groups, $7 \%$ of my time providing clinical services, and so on. In addition, I developed a resource base of written materials and audio and video recordings on topics related to farm stress. In later years, I added consulting, teaching, and research to the program.

I provided on-site education primarily in a workshop format, which included topics such as farm stress, anger and grief in the rural context, coping with change and loss, negotiating skills, and stress resiliency. For reasons discussed below, I did not just pick a topic and a date and advertise a workshop; a community group had to invite me. In the last nine years, I have conducted hundreds of workshops with thousands of rural people from churches, regional colleges, self-help groups, and front-line volunteer organizations. Some of these workshops have been aired across the province by the media; some broadcasts also have included a call-in component.

Developing and maintaining support groups did not turn out as 1 expected. Instead of directly developing such groups, I became more of a consultant or resource to groups which already existed. Occasionally I was asked to provide information about self-help groups; but, for the most part, groups evolved on their own.

Since $7 \%$ of the need expressed was for clinical work, I always reserved time for this component. I saw few clients individually because it was too time-consuming; however, when I did, 1 often learned from these clients important things that could be applied to my community work.

The general information component expressed in the needs assessment took the form of a resource base developed for the RQLP. It consisted of handouts which I either gleaned from a variety of agencies and institutions or wrote myself. These handouts-which cover such topics as helping one another through crisis, rural stress and what to do about it, coping with change and loss, coping with the loss of the farm, and how to find a job using skills learned on the farm-were important for many reasons, not the least of which was disseminating information to those people who needed the support, but were not attending the workshops. Participants could take the handouts home and leave them where people had the privacy to learn about one of the topics without fear of stigmatization. In addition to handouts, I made and acquired audio cassettes (which could be played in tractors or cars) and videotapes (which were most commonly used at health fairs). An Internet site has been developed for farm stress (http://www.health.gov.sk.ca/ps farmstress.html).

Over the years, as 1 got to know the people and their issues, gained their trust and credibility, and conducted research on topics related to farm stress, I was able to increase my involvement in advocacy, which also was identified in the needs assessment. This advocacy has taken many forms, including meeting with govern- 
ment officials, sitting on policy committees, providing evidence for needed change in policies and procedures, and publicizing the farm stress situation in interviews and articles. Through the appropriate and responsible use of the media, individual farmers, service agencies, program developers, politicians, government, and academics have come to be better aware of, to accept, and to take action about the problem of farm stress.

\section{Processes Used to Deliver Program}

Overarching these specific components were the processes used to deliver the program. The two most significant of these were community development and mental health promotion.

Community development, working with the community to enhance its capacity to accomplish whatever it decides, was an important part of this program (for a discussion of the practice of community development, see Gerrard, 1998). The process of my community development work, based on a model adopted from Kramer (1986), began with the needs of the community: interest in an issue developed from the needs; involvement came from the interest; ownership followed interest: then came co-operation and collaboration. The process was not linear; it kept returning to previous steps as development occurred.

The needs assessment which I conducted in the community not only identified the needs, it also sparked community interest. Because community development is about a shift in power relations, I decided not to go into a community uninvited. Members of the community heard about possible workshop topics through brochures, the media, or word of mouth, but they had to get involved in order to initiate my participation. They had to assume ownership and to decide when, and how, they wanted my involvement. Usually. I received an invitation to conduct a workshop within the community. The workshops, in and of themselves, also enhanced ownership because, as Cornish and Gerrard (1995) discuss, they encouraged "community members to participate meaningfully in their learning or development, thereby acquiring a sense of ownership over the process and authority over their own experience of it. ${ }^{-}$(p. 443) After presenting a workshop, I often was asked to co-operate in some community venture such as organizing a crisis line or producing a health fair. Over the years, this co-operation became collaboration, as I conducted projects and community-based and participatory-action research (in which those being researched participate in and share the ownership of the research and the research results in some sort of action) in the area of rural mental health.

In practice, I developed what 1 call the five-finger approach to community development. The thumb is the vision, which interacts with all the other fingers. In any order, one finger represents education (i.e., my workshop presentations). Another finger refers to the tools that assist people to get where they want to go (in the RQLP, it's the resource base or the consultation to form and maintain support groups or conduct research about some relevant topic). The next finger represents nurturance and support so that the people are not alone as they tackle their problems. The final finger represents a benchmark, some way of assessing whether or not one is going in the right direction. All together, the five-finger approach pro- 
vides a structure which encourages the creativity, co-operation, and collaboration described by Kramer (1986).

The RQLP engaged in a number of activities that promote mental health-that is, which strengthen peoples' resiliency, teach them the skills to handle adversity, promote healthy lifestyle choices, and address the determinants of health (see, e.g.. CPHA, 1997; Hamilton \& Bhatti, 1996).

Questions asked by workshop participants helped to inform me about the immdiate concerns of their lives and influenced the development of workshop topies (such as negotiating skills, means of coping with change or loss, and anger and grief in the rural context). Teaching the skills of navigating rural life addressed the risk and protective factors referred to in a health-promotion framework. Because the topies came from the people themselves, their relevance was assured.

One large community-based project was an effort to compete for funding from Health Canada for a Centre of Excellence for Rural Women's Health. I coordinated the proposal submission, which was the collaborative work of more than 250 women. Although the application did not receive funding, the effort resulted in the creation of a Rural Women's Health Partnership. Subsequently, the Partnership received funding for a conference on rural women's health and produced a report which has been used to educate others about rural women's health issues and to lobby government and health districts for change. The conference promoted mental health by bringing women together, breaking their isolation, and creating an environment of support, education, and nurturance.

At the request of one of the farm women's organizations, RQLP was able to get funding to conduct research on the health-related impacts of the erosion of support programs for farm women (Gerrard, Russell, \& SWAN, 1999). This research highlighted the relationship between numerous health determinants (such as isolation, lack of support, economic hardship, lack of educational and cultural opportunities) and the lack of government funding for farm women.

Other health promotion projects which were part of this community psychology approach to farm stress included rural women's discussion groups, an agricultural safety health fair, and a forum on unpaid work. All of them dealt with one or more of the determinants of health which are central to mental health promotion.

\section{DISCUSSION}

\section{Evaluation of the RQLP}

In 1993, a student from the University of Saskatchewan's Applied Psychology Program conducted an evaluability assessment of the RQLP (Meeres, Fisher, \& Gerrard, 1995). This work was the only process related to evaluation ever conducted on this program and, indeed, the only independent evaluative process of any program at the mental health clinic. However, it was not a complete evaluation, and assessment of the program remains dependent on anecdotal data. Many rural people have utilized the program (approximately 2,000 people attend over 30 workshops per year). For many reasons, evaluating the program's community development component is difficult and, although new methods are being developed to capture the effectiveness and outcomes of community development 
(e.g., Saskatoon District Health \& Labonte, 1999), further work needs to be done in this area.

\section{Conceptualization of Individuals-in-Communities}

I have shown in this paper how community psychology works within a framework of the community. Through an examination of the history, values, beliefs, and practices of community psychology and a discussion of its application to farm stress, I have demonstrated how individuals are viewed within the context of their community. The relationship between individuals and their communities, conceptualized herein as individuals-in-communities, is important to the practice of community psychology and makes a valuable contribution to the field of mental bealth theory, research, and practice.

In the 30 years that 1 have worked as a mental health practitioner, I have observed a service which too frequently forgets that individuals are not islands unto themselves. Generally, women who are victims of violence do not violate themselves; someone else does it to them. Racialized people (see Gerrard \& Javed, 1998) generally do not oppress themselves through racism; a society which believes in dominance does that to them. People who live in poverty do not choose to go without money for food, clothing, or shelter. Farmers do not choose to spend more money growing crops than they can earn by selling them. Our society provides the context within which these situations exist. Large groups of people share experiences which directly affect their mental health in both positive and negative ways. It is impossible to work with people who share issues and not see them as individuals-in-communities.

When we do not see individuals as individuals-in-communities, we can casily end up blaming the victim, exceptionalizing people (so that they feel isolated. alone, and helpless), and focusing treatment on the few (when the treatment not only applies to many, but is simply not available in sufficient quantities to ensure that all those who need and want it will have access to it). Too often we send individuals back to situations which are unhealthy and/or unsafe. In the mental health business, we refer to these individuals as revolving-door clients or patients. For instance, if abuse is the issue, victims will go home and get re-abused and come back for treatment (if it's available). Farmers develop depression and anxiety disorders because they feel like personal failures when their farm is in trouble. They aren't treated as if they are part of a greater whole which includes factors greater than themselves.

When we conceptualize individuals as individuals-in-communities, there are profound benefits:

1. The isolation of individuals is decreased. They no longer feel alone or blamed for what is happening to them. They see the massive power which forces larger than themselves bring to bear on their situation. For example, farmers who participate in some way in the RQLP begin to see themselves as part of a much bigger whole. They better understand their current situation as part of broader economic, political, and social forces. As they come together at workshops where these things are discussed, their sense of isolation and self-blame is diminished and community strengths are enhanced. 
2. Efforts to assist people are more efficient, since larger numbers of people are involved in interventions.

3. Our analysis of problems which affect peoples' mental health is aided by seeing the macro picture-which consists of trends and relationships often not visible at the micro (or individual) level. The development of programs and services to address these problems is aided by this macro analysis.

4. It is possible to attend to the health and viability of communities. Communities are entities unto themselves and contain individuals. A healthy community has major benefits for healthy individuals and a healthy society.

In my research on stress resiliency in rural people in Saskatchewan (Gerrard. 2000), healthy communities were described as those in which support, good communication, services, and resourees were available. As one person said, "I don't think it's [personal control-a cornerstone of mental health] about individual people being in control, it's about people being in control together" (p. 73). Most importantly, a participant in the resiliency research summed it up as follows:

We just don't realize it at times that we have to work together to make it go and we can't put somebody else down and not put ourseives down. Because I find if you help, if everybody is successful in a community then all of us will be successful, but if we are not successful we all suffer for it (p, 67),

\section{CONCLUSION: CONSIDERATIONS FOR FUTURE APPLICATIONS}

There are numerous considerations when contemplating future applications of community psychology to farm stress or other issues. The factors which make the RQLP unique-basing the program on the results of a needs assessments, using a community-development approach, and socially contextualizing the issue-are both strengths and liabilities. It took me two months to complete the needs assessment for the program, time which is often not available to staff. Designing the program as a direct response to the needs assessment results requires flexibility, freedom. and trust on the part of management. Because I had conducted the needs assessment myself, I had intimate knowledge of the content, not all of which was tangible, and carried that into the planning and implementation stages of the program. An added benefit for me was the ability to develop an understanding of and appreciation for rural culture. New staff who weren't involved in the needs assessment don't always have that same sense of detail, depth of understanding of the issue, and acculturation to rural life.

I have written extensively about the limitations of a community-development approach (Gerrard, 1998). In brief, the main issues are: (a) by changing the power relations from the top down to the bottom up, a community developer does not have control of the outcome: (b) building relationships, which is the cornerstone of community development, takes time and resources, both of which are often in short supply: (c) there is a great amount of risk and sense of vulnerability on behalf of the community developer: (d) community development takes a long time; and (c) the process requires support from management, peers, and the community itself.

Not all issues, though, lend themselves to a community development approach. I believe the main criteria for using this approach include: (a) the problem 
affects more than one person, (b) the solution affects more than one person, and (c) there has to be the potential to impact change.

From my perspective as a community psychologist, socially contextualing the issue of farm stress is essential. However, in the mainstream mental health system where training and programs are directed primarily at individual interventions, there often is resistance to this approach. In addition, traditional counsellors are reluctant to change from an individual-focused to a social-context perspective; the latter requires them to let go of the belief that their intervention is the critical variable in the progress of the client.

Farmers, on the other hand, have offered nothing but positive feedback about the program. They like being asked what they want and then having what they say put into action. They like the respect, mutuality, and shared power of a community-development approach. Further, they have told me that socially contextualizing the problem has been a great relief to them; it has allowed them to stop blaming themselves for their situation.

I was surprised to learn that no similar farm-stress programs are in place elsewhere in Canada. As a result, I have gone to provinces as distant as Prince Edward Island to work with farmers, agricultural resource people, and mental health staff. I also have conducted training workshops in other provinces for service providers who work with those suffering from farm stress. To create a program like the RQLP. I first suggest that staff in each area spend some time conducting a needs assessment. Doing so will help staff both to identify the local issues and to garner local interest, involvement, and ownership. Sharing power and partnering with farmers and farm groups is best done through a communitydevelopment approach. Bringing a social-context perspective to the issue ensures that re-victimization will not occur.

Because of the success of the RQLP, Saskatchewan Health has developed a contract position for a farm stress consultant for the entire province. Having now assumed this position, my main role is to enhance the capacity of both stakeholders and health districts to respond to farm stress. In this work, I make use of the philosophy and components of the RQLP, and focus on working within a healthpromotion framework and with health-promotion staff, interdepartmental staff, and anyone who has an interest in and commitment to dealing with the problem of farm stress. In addition, I am working with various departments and branches to develop a long-term plan for rural health. This plan will suggest policies for the long-term sustainability, health, and well-being of rural people in Saskatchewan.

The same perspective and skills which $I$ have employed in the RQLP can be (and, indeed, have been) used by others, regarding other issues (both urban and rural). In fact, community psychologists in Canada have been involved in addressing issues as diverse as teen prostitution in Toronto, sexual abuse, women's mental health, affordable housing, sexual harassment in schools, improving counselling programs in prisons, numerous Aboriginal issues, and the use of co-operatives for social, economic, and/or political change. Core to all of this work is an appreciation of the role of social context in the issue, a commitment to equal power relations with the community, and methods which partner the community psychologist with the community. 
Despite the demonstrated value and importance of the application of a community psychology perspective and skills to many and varied mental health issues, the future of community psychology as a discipline is unsure. Academic training programs have been decimated. The community psychology program at OISE, for example, has been eliminated due to financial restraints, as has the program's Ph.D. and Ed.D, degrees in community psychology. Further, I was only able to identify one current Canadian graduate program in community psychology (which offers an MA degree), as compared to four graduate programs which existed in the late $1980 \mathrm{~s}$. Services which are dedicated to lining clients up at the door and taking them one at a time continue to predominate the mental health industry, despite both the lack of resources for this kind of service and the evidence that the new health frameworks-which promote health (e.g. determinants of health and population health) and which are consistent with community psychology values and practices-have the potential to make much better use of resource dollars.

Community psychology provides the perspective and skills to deal with an issue such as farm stress. Working with individuals-in-communities to enhance their strengths, to overcome their barriers, and to develop support, resources, and mutual commitment leads to stronger, healthier, more resilient communities. It creates an environment in which the effects of the problem can be minimized and provides communities with the capacity to deal with emotional adversity. Further, this kind of environment facilitates actions directed towards reducing the causes of the problem, and often enables communities to make substantive positive changes at the social-context levels which will lead to the increased health of individuals within the communities, of the communities themselves, and of society as a whole.

\section{RÉSUMÉ}

La psychologie communautaire a vu le jour dans les années 1960 aux ÉtatsUnis, en réaction à deux phénomènes principaux. D'une part, la demande pour des soins en santé mentale basés sur la communauté a augmenté et d'autre part, les psychologues cliniciens ont commencé à mettre en doute ta conceptualisation et le traitement individuels de problèmes affectant un large ensemble de per-sonnes. Ils ont pris conscience que l'environnement social de leurs clients et clientes exerçait une influence de première importance sur la santé émotive de ceux-ci. En 1990, j'ai adopté une approche psychologique communautaire dans la conception et l'implantation en Saskatchewan d'un programme sur le stress causé par la vie sur la ferme. Mon article décrit comment les valeurs et pratiques issues de la psychologie communautaire, ainsi que les concepts de développement communautaire et de promotion de la santé mentale se sont concrétisés dans le cadre de ce programme. J'y examine également la perti-nence de la conceptualisation des questions de santé mentale, telles que le stress relié à la vie sur la ferme, du point de vue des individus vivant en communauté. Finalement, j'émet certaines considérations concernant de futures applications des principes de psychologie communautaire à des questions de santé mentale similaires ou autres. 


\section{REFERENCES}

Canadian Public Health Association. (1997). Health impacts of social and economic conditions: Implications for public policy. Ottawa: Author.

Cornish, P. \& Gerrard, N. (1995). Stress and the farm crisis: Towards the development of a synergistic theory of empowerment. In H. McDuffie, J. Dosman, K. Semchuk, S, Olenchock, \& A. Senthilselvan (Eds.), Agricultural health and safery: Workplace, environment, sustainability (pp. 439-444). Boca Raton, FL: Lewis Publishers.

Gerrard, N. (1995). Farm stress: A community development approach to mental health service delivery. In H. McDuffie, J. Dosman, K. Semchuk, S. Olenchock, \& A. Senthilselvan (Eds.). Agricultural health and safery: Workplace, environment, sustainability (pp. 433-438). Boca Raton, FL- Lewis Publishers.

Getrard, N. (1998), Community development: A new model for dealing with farm stress, In W. Thurston, J. Sieppert, \& V. Wiebe (Eds.), Doing health promotion research: The science of action (pp. 207-219). Calgary: Univetsity of Calgary.

Gerrard, N. (2000), What doesn't kill you makes you stronger: Determinants of stress resiliency in rural people in Saskatchewan. (Unpublished report). Saskatoon, SK: Author.

Gertard, N., \& Javed, N. (1998). Psychology of women. In N. Mandel (Ed.). Feminist issues: Race, class and seruality (2nd ed.). Toronto: Prentice-Hall.

Gerrard, N, Russell, G., \& Saskatchewan Women's Agricultural Network (SWAN). (1999). An exploration of health-related impacts of the erosion of agriculturally focused support programs for farm women in Saskatchewan. (Unpublished report). Saskatoon, SK: Author.

Gordon, E. (1990). Stress in the farm family: Implications for adult education. Unpublished master's thesis, University of Saskatchewan.

Hamilton, N., \& Bhatti, T. (1996). Population health promotion: An integrated model of populations health and health promotion. Ottawa: Health Promotion Development Division, Health Canada.

Keating, N. (1987). Reducing stress of farm men and women. Family Relations, 36, 358363.

Kramer, T. (1986). Mental health and the workplace project: Evaluation phase II/phase III. Toronto: Canadian Mental Health Association.

Meeres, S., Fisher, R., \& Gerrard, N. (1995). An evaluability assessment of a community based program. Canadian Joumal of Program Evaluation, 10(1), 103-121.

Phares, E., \& Trull, T. (1997). Clinical psychology: Concepts, methods and profession (5th ed.). Pacific Grove, CA: Brooks/Cole Publishing Co.

Pipke, L., Svenson, K., \& Dreidger, F. (1987), There are no more dreams: A proposal for action in the support of farm families in Saskatchewan. Regina: Family Service Bureau,

Rappaport, J. (1977). Community psychology: Values, research and action. New York: Holt, Rinehart and Winston.

Saskatoon District Health \& Labonte, R. (1999). Working upstream: Discovering effective practice strategies for community development in health. Saskatoon. SK: Prairie Region Health Promotion Research Centre and Saskatoon District Health, Community Development Team.

Walker, L. \& Walker, J. (1988). Self-reported stress symptoms in farmers. Joumal of Clinical Psychology, 44(1), 10-16. 